\title{
Genotypic Diversity of Theileria orientalis Detected from Cattle Grazing in Kumamoto and Okinawa Prefectures of Japan
}

\author{
Naoaki YOKOYAMA ${ }^{1) *}$, Akio UENO ${ }^{1)}$, Daisuke MIZUNO ${ }^{1}$, Noritaka KUBOKI ${ }^{1)}$, Altangerel KHUKHUU ${ }^{1)}$, \\ Ikuo IGARASHI ${ }^{1)}$, Tokuji MIYAHARA ${ }^{2)}$, Takashi SHIRAISHI ${ }^{3)}$, Ryuta KUDO ${ }^{4)}$, Mamoru OSHIRO ${ }^{5}$, \\ Satoshi ZAKIMI ${ }^{5}$, Chihiro SUGIMOTO ${ }^{6}$, Kotaro MATSUMOTO $^{7}$ and Hisashi INOKUMA $^{7)}$ \\ ${ }^{1)}$ National Research Center for Protozoan Diseases, Obihiro University of Agriculture and Veterinary Medicine, Obihiro, Hokkaido 080- \\ $8555,{ }^{2}$ The Chemo-Sero-Therapeutic Research Institute, Kumamoto, Kumamoto 860-8568, ${ }^{3)}$ Aso Animal Hygiene Service Center of \\ Kumamoto Prefecture, Aso, Kumamoto 869-2612, 4) Jonan Animal Hygiene Service Center of Kumamoto Prefecture, Hitoyoshi, \\ Kumamoto 868-0042, 5) Okinawa Prefectural Institute of Animal Health, Naha, Okinawa 900-0024, ${ }^{6}$ Research Center for Zoonosis \\ Control, University of Hokkaido, Sapporo, Hokkaido 001-0020 and ${ }^{7}$ Department of Clinical Veterinary Science, Obihiro University of \\ Agriculture and Veterinary Medicine, Obihiro, Hokkaido 080-8555, Japan
}

(Received 16 June 2010/Accepted 8 October 2010/Published online in J-STAGE 22 October 2010)

ABSTRACT. Theileria orientalis is a benign protozoan species that is widely distributed in Japan, yet sometimes causes serious economic losses in the livestock industry. In this study, we conducted a molecular survey based on genes encoding the major piroplasm surface protein (MPSP) and p23 for T. orientalis detected in cattle grazing in southern areas of Japan, consisting of 2 farms in Kumamoto prefecture (Aso and Kuma districts) and 3 farms in Okinawa prefecture (Ishigaki, Iriomote, and Yonaguni Islands). High prevalence rates of $T$. orientalis infection were shown in all the cattle populations using the diagnostic MPSP- and p23-PCR assays. Phylogenetic analyses revealed 4 MPSP genotypes and 3 p23 genotypes. Furthermore, MPSP genotype-specific PCR methods were developed in this study and wide distributions of 5-district genotypes of $T$. orientalis were observed for the examined farms. Our results indicate that at least 5 types of $T$. orientalis exist in Kumamoto and Okinawa prefectures of Japan and that genotype-specific PCR assays are highly applicable for the quarantine of transported cattle and for epidemiological surveys of bovine theileriosis in Japan. KEY WORDS: cattle, genotype-specific PCR, Japan, MPSP gene, Theileria orientalis.

Theileria orientalis, a tick-transmitted, intraerythrocytic protozoa belonging to the phylum Apicomplexa [4], is the causative organism of bovine theileriosis in Japan. T. orientalis is a member of the relatively benign Theileria group (Theileria sergenti/buffeli/orientalis) that is widely distributed throughout Japan [17]. Generally, it shows a lower pathogenicity in cattle compared to Theileria parva and Theileria annulata; however, it sometimes causes clear symptoms, including fever, anemia, and anorexia [13]. Flumethrin pour-on treatment is currently used to control the parasite in grazing cattle by reducing the number of vector ticks during pasture [11]. However, many farmers in Japan experience losses in livestock production because of the consequences of bovine theileriosis [7, 12]. In the Kyushu and Okinawa areas, the southern islands of Japan, the livestock industry for cattle has prospered; however, the practice of pasturing cattle to reduce rearing costs is associated with a high risk of contracting theileriosis.

Major piroplasm surface protein (MPSP) and p23 of $T$. orientalis are major immunodominant proteins expressed on the surface of the parasite during its intraerythrocytic (piroplasm) stage and show significant sequence diversities among field isolates of $T$. orientalis $[4,5,7,9,10,19]$. $T$.

\footnotetext{
* Correspondence to: Yokoyama, N., National Research Center for Protozoan Diseases, Obihiro University of Agriculture and Veterinary Medicine, Inada-cho, Obihiro, Hokkaido 080-8555, Japan.

e-mail: yokoyama@obihiro.ac.jp
}

orientalis populations are currently known to consist of 8 genotypes worldwide, based on all registered MPSP gene sequences $[3,6,18]$. Our recent survey carried out in Hokkaido prefecture of the northern island of Japan, demonstrated that there are at least 4 genotypes of $T$. orientalis (types 1, 2, 4, and 5) in Japan [7]. Thus, the MPSP gene has potential as a novel molecular marker for epidemiological study of $T$. orientalis.

In this study, we analyzed blood samples collected from 70 cattle (Holstein and Japanese Black) grazing in the Kyushu and Okinawa areas, consisting of 2 farms in Kumamoto prefecture (Aso and Kuma districts) and 3 farms in Okinawa prefecture (Ishigaki, Iriomote, and Yonaguni Islands) in Japan. By determining the sequences of T. orientalis MPSP and $p 23$ genes that were detected in the infected cattle, we identified the genotype diversities for this parasite in the southern prefecture of Japan. Furthermore, we developed 5 different genotype-specific PCR methods and identified the district-based distribution of $T$. orientalis genotypes in each of the grazing cattle populations. Herein, we report the current molecular status of $T$. orientalis distributed in Kumamoto and Okinawa prefectures of Japan and discuss the future utility of genotype-specific PCR methods.

\section{MATERIALS AND METHODS}

Blood samples: Cattle examined in this study were grazed on each of 5 farms located in 2 areas of Kumamoto prefec- 


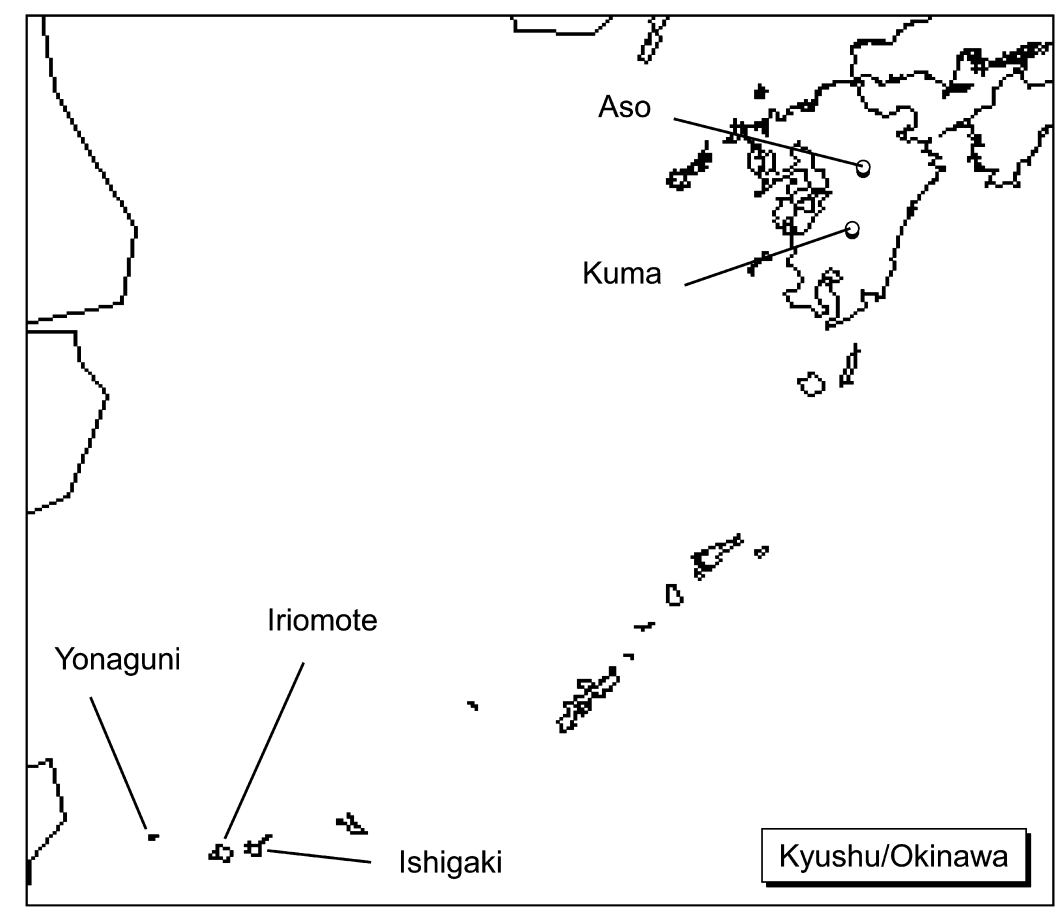

Fig. 1 Geographical map of the Kyushu and Okinawa areas in the southern islands of Japan. The locations where the blood samples were collected in the 5 districts or islands (Aso and Kuma in Kumamoto prefecture; Ishigaki, Iriomote, and Yonaguni in Okinawa prefecture) are shown.

ture (Aso and Kuma districts) and 3 areas of Okinawa prefecture (Ishigaki, Iriomote, and Yonaguni Islands) in Japan (Fig. 1). Farms were identified as $T$. orientalis-prevalent areas by field veterinarians. Holstein cattle aged from 8 months to 2 years were grazed for the first time on the Kuma district farm, while Japanese Black cattle from the Aso district farm were of various ages (3 to 14 years) and grazing histories. Japanese Black cattle in Okinawa prefecture also were of various ages (Ishigaki Island, from 8 months to 14 years; Iriomote Island, 7 months to 2 years; Yonaguni Island, from 7 years to 19 years) and had various grazing histories. All cattle were originally born in the same prefectures, except for three cattle in Aso district of Kumamoto prefecture that were born in other neighbor prefectures (either of Kagoshima or Miyazaki prefecture in Kyushu area) and then introduced to the Aso district. Three cattle in Iriomote Island were male and all other cattle were female. A total of 70 blood samples were collected from the grazing cattle late in the pasturage period during 2007 (Table 1).

Diagnoses of parasitemia and anemia: Approximately 2 $\mathrm{m} l$ of blood was collected from the tail veins of cattle and added to ethylenediaminetetraacetic acid (EDTA) to a final concentration of $0.15-0.22 \%$. Thin blood smears were made and then stained with Giemsa solution for classic microscopic diagnosis as described previously [7]. In addition, the hematocrit (HCT) values of the respective blood samples were determined and anemia was diagnosed if the
HCT value was $<24 \%$ [2].

DNA extraction and plasma preparation: Genomic DNA was extracted from $100 \mu \mathrm{l}$ of blood samples using a QIAamp ${ }^{\circledR}$ DNA Blood Mini Kit (Qiagen, Hilden, Germany) and $200 \mu l$ of eluted DNA (approximately $6 \mu \mathrm{g} / \mu l$ ) were obtained and stored at $30^{\circ} \mathrm{C}$ for subsequent PCR analyses. Blood plasma fractions were obtained by centrifugation of blood samples at $700 \times g$ for $15 \mathrm{~min}$ at $4^{\circ} \mathrm{C}$ and then stored at $-30^{\circ} \mathrm{C}$ for enzyme-linked immunosorbent assay (ELISA).

PCR: A classic universal PCR (product size: 857 base pairs $[\mathrm{bp}])$ assay, which had been previously designed for the MPSP (p32/33/34) gene of T. orientalis [14], and 2 kinds of recently developed PCR assays, MPSP-PCR (776 bp) and p23-PCR (601 bp) assays [7], were used for the diagnostic detection of $T$. orientalis genes, according to the previously described procedures.

Here, we designed 5 new primer pairs by aligning all of the registered sequences of MPSP genes listed in Fig. 2. These primer pairs were designed to specifically amplify the target DNA fragments for each of the 5 genotypes of MPSP genes (types 1-5 in Fig. 2) in the respective PCR analyses. Primer sequences, annealing temperatures and the resultant product sizes are summarized in Table 2. Each of the typespecific primer pairs specifically anneal to the conserved regions of MPSP gene sequences categorized only in the corresponding genotype groups. The PCR methods were evaluated as new diagnostic assays to survey actual type- 
Table 1. Diagnostic history of grazing cattle in southern areas of Japan

\begin{tabular}{|c|c|c|c|c|c|c|c|c|}
\hline \multirow{3}{*}{ Prefectures } & \multirow{3}{*}{$\begin{array}{l}\text { Districts } \\
\text { (Species) }\end{array}$} & \multirow{3}{*}{$\begin{array}{c}\text { Date }^{\mathrm{a})} \\
\text { (Total cattle) }\end{array}$} & \multicolumn{6}{|c|}{ Number of positive cattle (\%) } \\
\hline & & & \multirow{2}{*}{$\begin{array}{l}\text { Microscopic } \\
\text { test }^{\mathrm{b})}\end{array}$} & \multirow[b]{2}{*}{ Anemia ${ }^{\text {c) }}$} & \multirow{2}{*}{ ELISA $^{\text {b) }}$} & \multicolumn{3}{|c|}{ PCR } \\
\hline & & & & & & Universal $^{\text {b) }}$ & MPSPb) & p23 $3^{\mathrm{b})}$ \\
\hline \multirow[t]{2}{*}{ Kumamoto } & $\begin{array}{c}\text { Aso } \\
\text { (Japanese Black) }\end{array}$ & $12 / 18(15)$ & $15(100.0)$ & $0(0.0)$ & $15(100.0)$ & $15(100.0)$ & $15(100.0)$ & $15(100.0)$ \\
\hline & $\begin{array}{c}\text { Kuma } \\
\text { (Holstein) }\end{array}$ & $11 / 19(35)$ & $28(80.0)$ & $1(3.0)$ & $31(88.6)$ & $30(85.7)$ & $33(94.3)$ & $34(97.1)$ \\
\hline \multirow{3}{*}{ Okinawa } & $\begin{array}{c}\text { Ishigaki } \\
\text { (Japanese Black) }\end{array}$ & $9 / 4,14(10)$ & $10(100.0)$ & $0(0.0)$ & $6(60)$ & $9(90.0)$ & $10(100.0)$ & $10(100.0)$ \\
\hline & $\begin{array}{c}\text { Iriomote } \\
\text { (Japanese Black) }\end{array}$ & $11 / 28(5)$ & $5(100.0)$ & $0(0.0)$ & $0(0.0)$ & $5(100.0)$ & $5(100.0)$ & $5(100.0)$ \\
\hline & $\begin{array}{c}\text { Yonaguni } \\
\text { (Japanese Black) }\end{array}$ & $12 / 5(5)$ & $5(100.0)$ & $0(0.0)$ & $4(80.0)$ & $4(80.0)$ & $5(100.0)$ & $5(100.0)$ \\
\hline
\end{tabular}

a) Month/Date.

b) Number (\%) of cattle showing positive reactions (of total cattle).

c) Number (\%) of cattle showing clinical anemia in a group of MPSP PCR-positive cattle.

specific distributions of $T$. orientalis in each cattle population.

Type-specific PCR methods were performed using $1 \mu l$ of stored DNA template extracted from blood samples, mixed with $9 \mu l$ of reaction buffer consisting of $0.05 \mu l$ of Ex Taq DNA polymerase (Takara, Tokyo, Japan), $0.1 \mu l$ of $10 \mu \mathrm{M}$ each primer, $1 \mu l$ of $10 \times$ Ex Taq Buffer (Takara), $0.8 \mu l$ of dNTP mixture (2.5 mM each, Takara), and $6.95 \mu l$ of double distilled water (DDW). Reactions were carried out using an iCycler Thermal Cycler (Bio-Rad Laboratories, Hercules, CA, U.S.A.) for 35 cycles. After an initial denaturation step for $5 \mathrm{~min}$ at $94^{\circ} \mathrm{C}$, amplification consisted of denaturation for $30 \mathrm{sec}$ at $94^{\circ} \mathrm{C}$, annealing for $45 \mathrm{sec}$ at the indicated temperature (Table 2) and extension for $1 \mathrm{~min}$ at $72^{\circ} \mathrm{C}$, followed by an additional $7 \mathrm{~min}$ at $72^{\circ} \mathrm{C}$. The amplified PCR products were subjected to $2.0 \%$ agarose gel electrophoresis, stained with ethidium bromide and then visualized under an ultraviolet light.

ELISA: Classic serodiagnostic ELISA was performed using a crude parasite antigen to assess the presence of $T$. orientalis-specific antibodies in the collected blood plasma fractions, as described previously [7].

DNA sequencing and phylogenetic analyses: DNA sequencing analyses of PCR fragments were carried out to examine the diversities of MPSP and $p 23$ genes detected from the blood samples, as described previously [7]. At least 10,12 , and 15 blood samples were randomly selected from the diagnostic PCR-positive samples from Aso, Kuma, and Okinawa farms, respectively. DNA fragments were amplified by another PCR step for subsequent DNA sequencing of MPSP and $p 23$ genes [7]. In detail, PCR was performed using $2 \mu l$ of the selected DNA template, mixed with $18 \mu l$ of reaction buffer, consisting of $0.2 \mu l$ of Expand HiFi Plus Enzyme Blend (Roche Applied Science, Basel, Switzerland), $0.2 \mu l$ of $10 \mu \mathrm{M}$ of each primer, $4 \mu l$ of $5 \times$ Expand HiFi Plus Reaction Buffer with $7.5 \mathrm{mM} \mathrm{MgCl}_{2}, 0.4$ $\mu l$ of $10 \mathrm{mM}$ PCR Grade Nucleotide Mix (Roche Applied
Science) and $13 \mu l$ of DDW. All PCR cycles consisted of an initial denaturation step for $2 \mathrm{~min}$ at $94^{\circ} \mathrm{C}$, followed by 35 cycles for $1 \mathrm{~min}$ at $94^{\circ} \mathrm{C}$, annealing for $30 \mathrm{sec}$ at $58^{\circ} \mathrm{C}$ and extension for $1 \mathrm{~min}$ at $72^{\circ} \mathrm{C}$, followed by an additional $7 \mathrm{~min}$ at $72^{\circ} \mathrm{C}$. The amplified PCR products were cloned into a pCR2.1-TOPO vector, according to the manufacturer's instructions for the TOPO TA cloning kit (Invitrogen, Carlsbad, CA, U.S.A.). DNA sequencing of the inserts was performed commercially (Sigma-Aldrich, Tokyo, Japan). The CLUSTAL X program (University College Dublin, Dublin, Ireland) was used to align the obtained sequences and a neighbor joining method using an NJplot program [8] was used to construct 2 phylogenetic trees based on MPSP and $p 23$ genes. The accuracy of the phylogenetic tree branches was confirmed by a bootstrap method [1]. Representative sequences obtained in this study were registered in the GenBank database (National Center for Biotechnology Information, National Institutes of Health) (Figs. 2 and 3).

\section{RESULTS}

Detection of T. orientalis from grazing cattle: Although only 1 cattle showed anemia (Holstein in Kuma farm) among all the examined animals, results of the diagnostic MPSP- and p23-PCR assays, together with classic microscopic test and serodiagnostic ELISA, demonstrated high prevalent rates of $T$. orientalis in all populations examined (Table 1). As the case of a previous report [7], diagnostic MPSP- and p23-PCR assays were proven to show higher sensitivities for the detection of $T$. orientalis, as compared to the classic universal PCR assay. In addition, Japanese Black cattle in Iriomote Island gave a negative reaction when tested with the serodiagnostic ELISA, although the parasite was detected in all cattle, even using microscopy.

Phylogenetic analyses of isolated MPSP and p23 genes: For DNA sequencing of MPSP and $p 23$ genes, we randomly selected the PCR-positive blood samples from Aso, Kuma, 


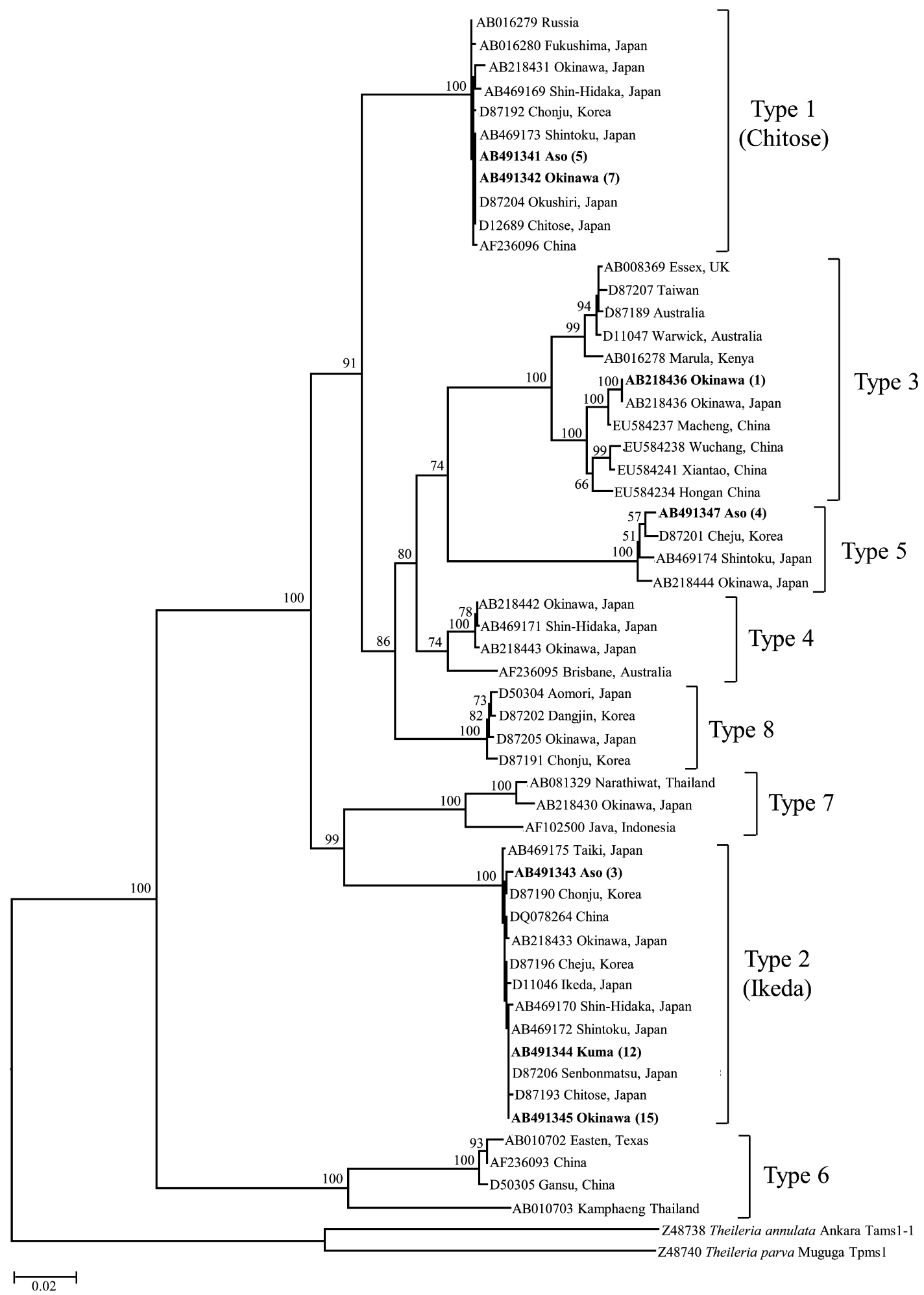

Fig. 2. Phylogenetic tree of the MPSP genes based on the results from blood samples collected in Kumamoto and Okinawa prefectures, together with previously registered sequences from the GenBank database. MPSP gene sequences determined in this study are shown (in boldface), together with the number of collected samples. The representative sequences of isolated MPSP genes refer to the GenBank accession numbers, as indicated at the end of each branch. The length of the horizontal bar indicates the number of nucleotide substitutions per site. Numbers shown at the branch nodes indicate the bootstrap values. 
Table 2. Primer sequences for T. orientalis genotype-specific PCR assays

\begin{tabular}{|c|c|c|c|c|}
\hline \multicolumn{2}{|c|}{ Primer Names } & Sequences & Annealing $\left({ }^{\circ} \mathrm{C}\right)$ & Product sizes \\
\hline MPSP1 & $\begin{array}{l}F^{\text {a) }} \\
R^{\text {b) }}\end{array}$ & $\begin{array}{l}5^{\prime}-\text { ttg cct agg ata ctt cct cat cg-3' } \\
5^{\prime} \text {-tgc got gta ttt goc ctt c-3' }\end{array}$ & 64 & 559 \\
\hline MPSP2 & $\begin{array}{l}\mathrm{F} \\
\mathrm{R}\end{array}$ & $\begin{array}{l}5 \text { '-cgc atc aag aca ctc aag gtc-3' } \\
5 \text { '-cac tgt tca tgg cgt gca-3' }\end{array}$ & 58 & 550 \\
\hline MPSP3 & $\begin{array}{l}\mathrm{F} \\
\mathrm{R}\end{array}$ & $\begin{array}{l}5 \text { '-agt cgc cca cag aat taa gca ta-3, } \\
5 \text { '-tta ccg gta ccg aat gta tca gct-3, }\end{array}$ & 66 & 228 \\
\hline MPSP4 & $\begin{array}{l}\mathrm{F} \\
\mathrm{R}\end{array}$ & $\begin{array}{l}5 \text { '-caa tga ggg att tcg cat c-3' } \\
5 \text { '-cga tga agt cgt aga cct t-3, }\end{array}$ & 55 & 326 \\
\hline MPSP5 & $\begin{array}{l}\mathrm{F} \\
\mathrm{R}\end{array}$ & $\begin{array}{l}5 \text { '-cag tca atg caa caa aac ccg a-3", } \\
5^{\prime \prime} \text {-ctt ttt agg atc acc gac atc cag-3, }\end{array}$ & 56 & 424 \\
\hline
\end{tabular}

a) Forward primer. b) Reverse primer.

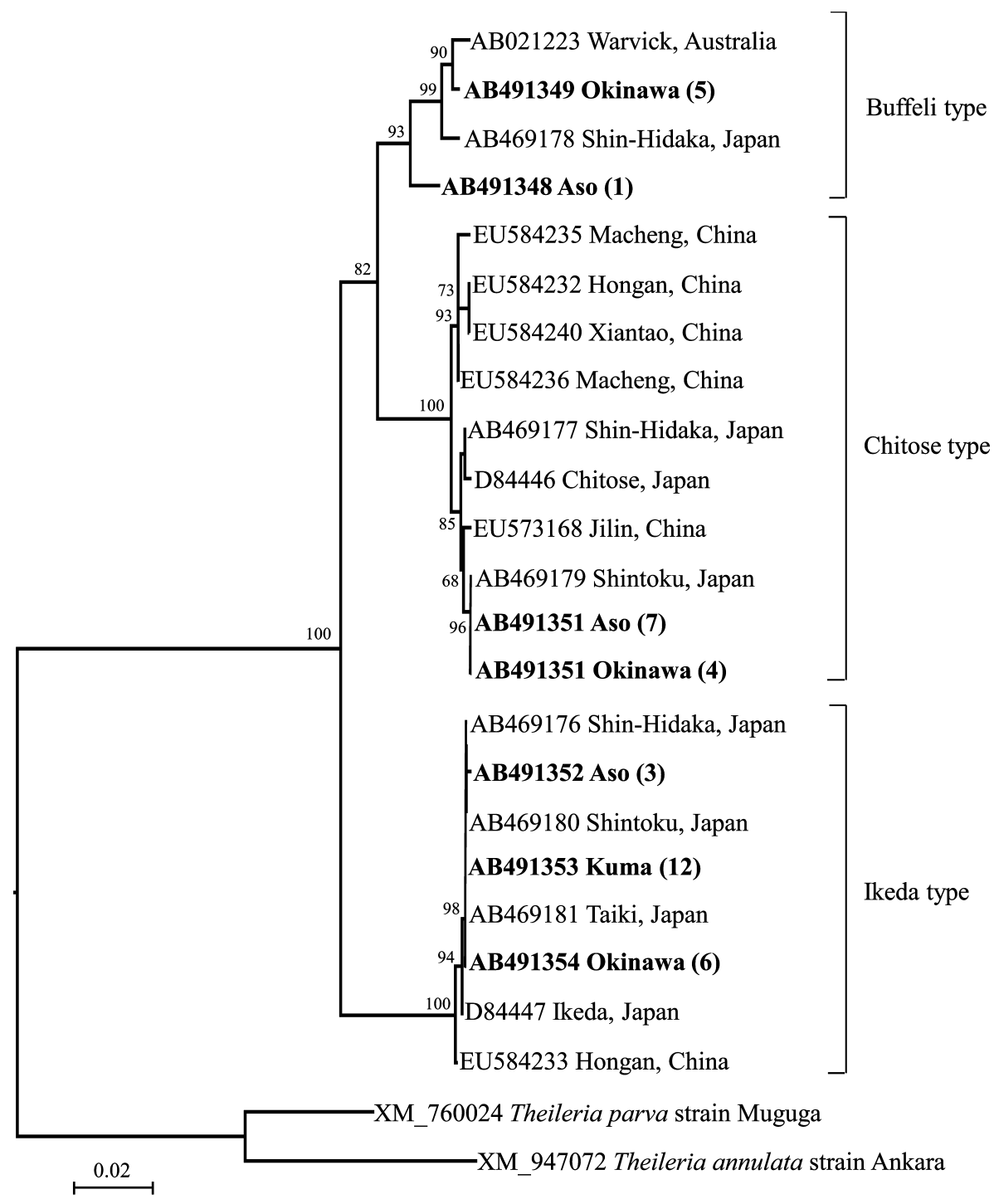

Fig. 3. Phylogenetic tree of the $p 23$ genes based on the results from blood samples collected in Kumamoto and Okinawa prefectures, together with previously registered sequences from the GenBank database. The p23 gene sequences determined in this study are shown (in boldface), together with the number of collected samples. The representative sequences of isolated $p 23$ genes refer to the GenBank accession numbers, as indicated at the end of each branch. The length of the horizontal bar indicates the number of nucleotide substitutions per site. Numbers shown at the branch nodes indicate the bootstrap values. 
A: Type 1-PCR
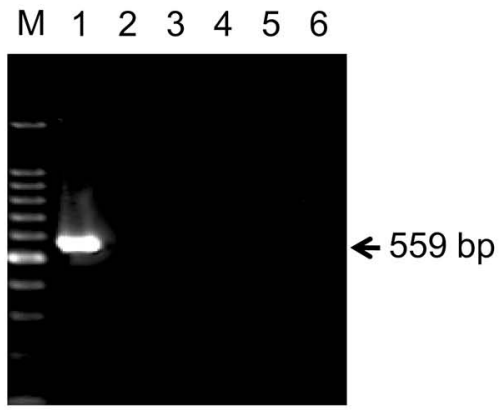

B: Type 2-PCR
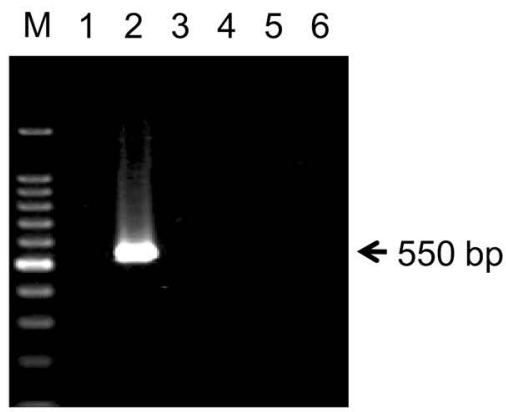

\section{Type 3-PCR}


D: Type 4-PCR
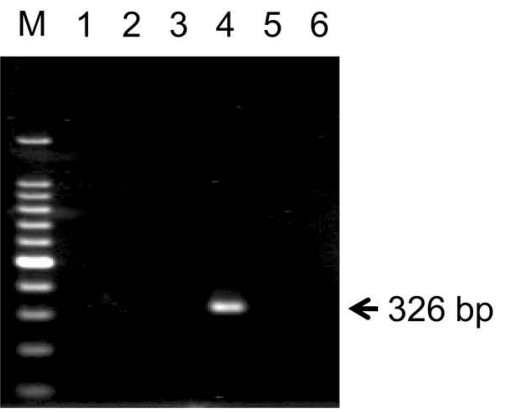

E: Type 5-PCR

$\begin{array}{lllllll}\text { M } & 1 & 2 & 3 & 4 & 5 & 6\end{array}$

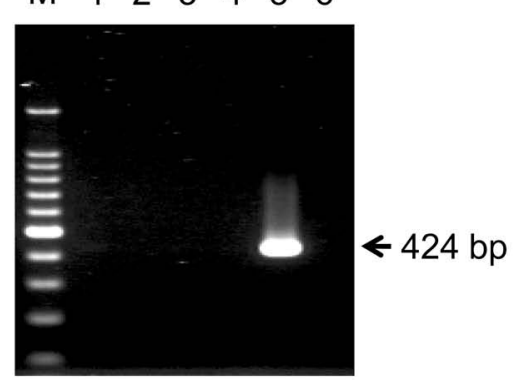

Fig. 4. Specific DNA amplifications of the 5 genotype-specific PCR methods (A-E). The specificity of each type-specific PCR method was evaluated using the plasmids containing 5 genotypes of MPSP genes as templates. In all panels, lane 1, type 1 gene (AB491341); lane 2, type 2 gene (AB491343); lane 3, type 3 gene (AB218436); lane 4, type 4 gene (AB469171); lane 5, type 5 gene (AB491347), and lane 6, pCR2.1-TOPO vector as negative control. Lane M, a 100-bp ladder size marker. Arrows on the right of each panel indicate the respective sizes of amplified DNA products that were identified using $2.0 \%$ agarose gel electrophoresis.

and Okinawa farms. Consequently, 47 and 38 PCR fragments derived from MPSP and p23 genes, respectively, were isolated and complete sequences determined. From the phylogenetic analysis of identified MPSP genes, we detected 4 genotypes of MPSP genes that were categorized as types 1, 2, 3, and 5 (Fig. 2). In Kuma farm, only type 2 (Ikeda type) of MPSP genes was isolated, while 3 district types of MPSP genes, including the type 2 gene, were detected from Aso and Okinawa farms. In contrast, all 3 genotypes of the p23 gene, consisting of Buffeli, Chitose, and Ikeda types, were successfully detected in this study, based on phylogenetic analysis of previously identified $p 23$ genes (Fig. 3). In Kuma farm, only the Ikeda type of p23 gene was isolated, while all 3 types of the p23 gene were detected from Aso and Okinawa farms. Consequently, 4 and 3 types of MPSP and p23 genes, respectively, were detected in this study.

Wide distributions of 5 district genotypes of T. orientalis in cattle populations: Four genotypes of MPSP gene (types $1,2,3$, and 5) were detected in the southern prefectures of Japan, in contrast to the different set of MPSP genotypes (type 1, 2, 4, and 5) that we reported in a previous study for the northern area [7]. These findings indicate that at least 5 genotypes of $T$. orientalis (types 1-5) currently exist in
Japan. Therefore, we designed 5 genotype-specific PCR methods that can identify the 5 genotypes of MPSP gene (Table 2), based on all the registered sequences of MPSP genes listed in Fig. 2. The specificities of the genotype-specific PCR methods were evaluated by using the respective plasmids containing the 5 genotypes of MPSP gene as templates. Type 1 PCR method amplified a 559-bp DNA band specific to the type 1 (Chitose type) MPSP gene and did not amplify any other MPSP genotypes (Fig. 4). The other typespecific PCR assays also exhibited the same specificities to the target types of MPSP gene. PCR evaluation of all plasmid samples, which we had constructed for the 5 types of MPSP gene in the present and previous studies (Fig. 2) [7], showed no change in the high specificities of genotype-specific PCR methods (data not shown).

Finally, we surveyed the actual distributions of the 5 genotypes of $T$. orientalis in each of the cattle populations using the developed genotype-specific PCR assays (Fig. 5). In Kumamoto prefecture, all 5 genotypes were highly detectable in the Aso population, while a dominant infection of $T$. orientalis type 2 was observed in the Kuma population. In contrast, only types 1 and 2 were detected in the Iriomote population, while all 5 genotypes were distributed in the Ishigaki and Yonaguni populations. Overall, the type-specific 
A: Aso

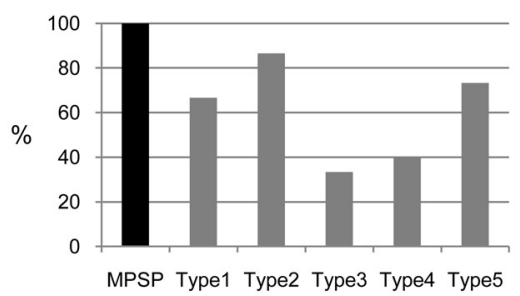

B: Kuma

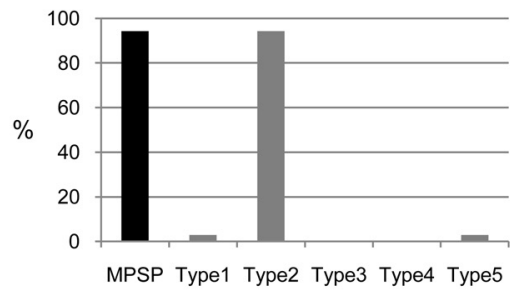

\section{C: Ishigaki}

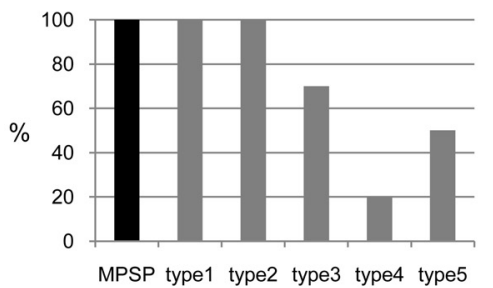

D: Iriomote

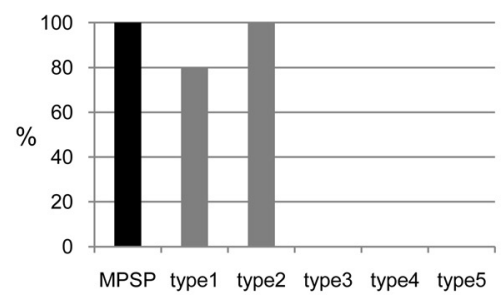

E: Yonaguni

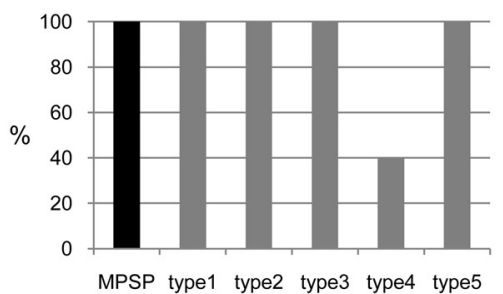

Fig. 5. MPSP genotype-specific distributions of T. orientalis in each cattle population grazing in Aso and Kuma districts in Kumamoto prefecture (A and B, respectively) and Ishigaki, Iriomote, and Yonaguni Islands in Okinawa prefecture (C, D, and E, respectively). All distribution values are expressed as the percentages of positive cattle for the 5 genotype-specific PCR assays (types 1-5) and diagnostic MPSP-PCR assay (MPSP).

PCR assays demonstrated wide distributions of the 5 district genotypes of $T$. orientalis in Kumamoto and Okinawa prefectures of Japan.

\section{DISCUSSION}

In this study, at least 5 genotypes of $T$. orientalis (types 1-5) were shown to currently exist in the southern areas of Japan. Combined with previous reports $[6,18]$, this study indicates that a total of 7 genotypes of $T$. orientalis possibly exist in Japan, based on MPSP gene sequences (types 1, 2, $3,4,5,7$, and 8 ). The type 6 genotype of this parasite seems to form a distinct phylogenetic group from the family of benign $T$. sergenti/buffeli/orientalis group and has been previously detected in China, Thailand, and the United States [4]. In contrast, previous phylogenetic analysis of the $p 23$ gene indicated the presence of only 3-district genotypes, consisting of Buffeli, Chitose, and Ikeda types [9]. All 3 genotypes were successfully isolated in this study. Although the $p 23$ gene exhibited a relatively lower diversity than the MPSP gene, a greater phylogenetic complexity may become apparent when more detailed information on $p 23$ gene is accumulated from the field in the future. How and why such high diversities of MPSP and p23 genes occur among field isolates of $T$. orientalis remain unclear and further epidemiological studies are required to understand the molecular diversity and wide distribution of $T$. orientalis.

Infection rates detected during our study do not reflect all farms in Kumamoto and Okinawa prefectures as we focused on farms that were suspected to be prevalent for T. orientalis. However, it is clear that T. orientalis is distributed throughout these prefectures, with a total of 5 MPSP genotypes identified, taking into account the results of our previous study [7]. Furthermore, with the aid of cloned plasmids, we successfully constructed 5 genotype-specific PCR methods that have the potential as diagnostic assays for the identification of actual infection rates for each genotype in each population. The results of the genotype-specific PCR analyses demonstrate the original distributions of 5 district genotypes of $T$. orientalis in the examined farms. Interestingly, dominant distributions of 1 or 2 genotypes were observed in the Kuma and Iriomote farms, while all genotypes of T. orientalis were widely distributed in the Aso, Ishigaki, and Yonaguni farms. Almost all Japanese Black cattle were infected with multiple parasite genotypes.

Terada et al. [15] reported that the indigenous Japanese Black breed of cattle was more resistant to $T$. orientalis infection than the exotic Holstein. Our previous report [7] also showed that the Japanese Black cattle showed no sign of anemia, although the exotic Holsteins and Herefords showed a high rate of anemia in the grazing field. Additionally, we recently reported significantly lower immunological responses of the Japanese Black cattle against $T$. orientalis infection, as compared to Holsteins [16]. Such unique characteristics of the Japanese Black cattle are supported by this breed in Iriomote Island giving a negative reaction in the serodiagnostic ELISA. The possibility that Japanese Black cattle resistant to T. orientalis might become 
infectious carriers of multiple genotypes of $T$. orientalis is also highly interesting, but further epidemiological survey using the genotype-specific PCR assays is required to prove this.

This study indicated that at least 5 types of $T$. orientalis exist in Kumamoto and Okinawa prefectures of Japan and that genotype-specific PCR assays have useful applications in the quarantine of transported cattle and epidemiological surveys of bovine theileriosis in Japan.

ACKNOWLEDGMENTS. We thank all the staff of the study farms in Kumamoto and Okinawa prefectures for their kind cooperation. In addition, we also thank Ms. Hiroko Yamamoto for her excellent technical assistance. This study was supported by a program for the Promotion of Basic Research Activities for Innovative Biosciences (PROBRAIN), a grant from the Global COE Program from the Japanese Ministry of Education, Science, Sports, Culture and Technology and Grants-in Aid for Scientific Research from the Japan Society for Promotion of Science (JSPS), Japan.

\section{REFERENCES}

1. Felsenstein, J. 1985. Confidence limits on phylogenies: an approach using the bootstrap. Evolution 39: 783-791.

2. Jain, K. 1993. Essentials of Veterinary Hematology. Blackwell Publishing, U. S. A.

3. Jeong, W., Yoon, S. H., An, D. J., Cho, S. H., Lee, K. K. and Kim, J. Y. 2010. A molecular phylogeny of the benign Theileria parasites based on major piroplasm surface protein (MPSP) gene sequences. Parasitology 137: 241-249.

4. Kakuda, T., Shiki, M., Kubota, S., Sugimoto, C., Brown, W. C., Kosum, C., Nopporn, S. and Onuma, M. 1998. Phylogeny of benign Theileria species from cattle in Thailand, China and the U.S.A. based on the major piroplasm surface protein and small subunit ribosomal RNA genes. Int. J. Parasitol. 28: 1261-1267.

5. Kawazu, S., Sugimoto, C., Kamio, T. and Fujisaki, K. 1992. Analysis of the genes encoding immunodominant piroplasm surface proteins of Theileria sergenti and Theileria buffeli by nucleotide sequencing and polymerase chain reaction. Mol. Biochem. Parasitol. 56: 169-175.

6. Kim, J. Y., Yokoyama, N., Kumar, S., Inoue, N., Yamaguchi, T., Sentoku, S., Fujisaki, K. and Sugimoto, C. 2004. Molecular epidemiological survey of benign Theileria parasites of cattle in Japan: detection of a new type of major piroplasm surface protein gene. J. Vet. Med. Sci. 66: 251-256.

7. Ota, N., Mizuno, D., Kuboki, N., Igarashi, I., Nakamura, Y.,
Yamashina, H., Hanzaike, T., Fujii, K., Onoe, S., Hata, H., Kondo, S., Matsui, S., Koga, M., Matsumoto, K., Inokuma, H. and Yokoyama, N. 2009. Epidemiological survey of Theileria orientalis infection in grazing cattle in the eastern part of Hokkaido, Japan. J. Vet. Med. Sci. 71: 937-944.

8. Perriere, G. and Gouy, M. 1996. WWW-query: an on-line retrieval system for biological sequence banks. Biochimie 78: 364-369.

9. Sako, Y., Asada, M., Kubota, S., Sugimoto, C. and Onuma, M. 1999. Molecular cloning and characterisation of 23-kDa piroplasm surface proteins of Theileria sergenti and Theileria buffeli. Int. J. Parasitol. 29: 593-599.

10. Sako, Y., Sugimoto, C. and Onuma, M. 1999. Expression of a major piroplasm surface protein of Theileria sergenti in sporozoite stage. J. Vet. Med. Sci. 61: 275-277.

11. Shimizu, S., Nojiri, K., Matsunaga, N., Yamane, I. and Minami, T. 2000. Reduction in tick numbers (Haemaphysalis longicornis), mortality and incidence of Theileria sergenti infection in field-grazed calves treated with flumethrin pouron. Vet. Parasitol. 92: 129-138.

12. Shimizu, S., Yoshiura, N., Mizomoto, T. and Kondou, Y. 1992. Theileria sergenti infection in dairy cattle. J. Vet. Med. Sci. 54: 375-377.

13. Sugimoto, C. and Fujisaki, K. 2002. Non-transforming Theileria parasites of ruminants, vol. 3. Kluwer Academic Publishers, London.

14. Tanaka, M., Onoe, S., Matsuba, T., Katayama, S., Yamanaka, M., Yonemichi, H., Hiramatsu, K., Baek, B. K., Sugimoto, C. and Onuma, M. 1993. Detection of Theileria sergenti infection in cattle by polymerase chain reaction amplification of parasite-specific DNA. J. Clin. Microbiol. 31: 2565-2569.

15. Terada, Y., Ishida, M. and Yamanaka, H. 1995. Resistibility to Theileria sergenti infection in Holstein and Japanese Black cattle. J. Vet. Med. Sci. 57: 1003-1006.

16. Yamaguchi, T., Yamanaka, M., Ikehara, S., Kida, K., Kuboki, N., Mizuno, D., Yokoyama, N., Narimatsu, H. and Ikehara, Y. 2010. Generation of IFN-gamma-producing cells that recognize the major piroplasm surface protein in Theileria orientalis-infected bovines. Vet. Parasitol. 171: 207-215.

17. Yamane, I., Koiwai, M., Tsusui, T. and Hamaoka, T. 2001. A survey of Theileria sergenti infection, daily weight gain and conception proportions in 85 herds of grazing heifers in Japan. Vet. Parasitol. 99: 189-198.

18. Zakimi, S., Kim, J. Y., Oshiro, M., Hayashida, K., Fujisaki, K. and Sugimoto, C. 2006. Genetic diversity of benign Theileria parasites of cattle in the Okinawa Prefecture. J. Vet. Med. Sci. 68: $1335-1338$.

19. Zhuang, W., Sugimoto, C., Matsuba, T., Niinuma, S., Murata, M. and Onuma, M. 1994. Analyses of antigenic and genetic diversities of Theileria sergenti piroplasm surface proteins. $J$. Vet. Med. Sci. 56: 469-473. 